\title{
Emotional Intelligence And Leadership Competencies: A Study Of Ministry Of Works, Owerri
}

\author{
Prof. Gideon A. Emerole \\ Department of Business Administration \\ Michael Okpara University of Agriculture, Umudike \\ Nwaji Charles \\ Department of Industrial Relations and Personnel Management \\ Michael Okpara University of Agriculture, Umudike \\ John Okpoyo Etifit \\ Department of Business Management \\ Imo State University, Owerri, Imo State
}

\begin{abstract}
The study examined Emotional Intelligence and Leadership Competencies: A Study of Ministry of Works, Owerri. In conducting the study, descriptive survey approach was adopted and data was generated from a five point likert scale questionnaire. The study covered a population of one hundred and twenty three (123) senior and junior members of staff of the ministry. Taro Yamene formula was used to select a sample of 94 respondents. Out of the 94 questionnaires distributed, 88 were correctly filled and returned; thereby given a questionnaire return rate of $93.62 \%$. The data gathered was analyzed with the kruskawalis $(\mathrm{H})$ test. The study found that Leadership competence is an integral component of organizational performance, hence, it was concluded that the emotional state of the leader has significant effect on his/her competence. The study therefore recommends that Leaders should demonstrate emotional self-control, transparency, adaptability, initiative and be optimistic. These are the inevitable high personal standards that drives them to constantly seek performance improvements, hence; enhancing their goal achievement orientation and that to develop quality social awareness, leaders should strive to exhibit conflict management skills, be inspirational, drive changes in their environment and develop others. These helps to generate an atmosphere of friendly collegiality and make them models of respect, helpfulness, and co-operation, thereby drawing others into active, enthusiastic commitment to the collective effort, and build spirit and identity.
\end{abstract}

KEYWORDS: Emotional intelligence, Leadership competencies, Self Awareness

\section{INTRODUCTION}

The past few decades have witnessed extraordinary transformations in the nature of work and organization. Globalization and heightened international competition have spurred a marked increase in mergers and acquisitions, as organizations position themselves to perform in the 21st Century world economy. The modern workplace has experienced a sustained period of delayering management structures, downsizing, and "offshoring," as organizations strive to contain costs and achieve more with fewer resources (Cartwright \& Holmes, 2006). Additionally, organizations have enlisted the massive advances in communications and information technology that have emerged during the last twenty years to streamline planning and decision-making processes, eliminate redundancy of effort, and enhance productivity. Such technologies have enabled collaboration in ways never before seen, which has led to an increase in the ability of organizations to compete globally via virtual teaming, but also to a decline in face-to-face or "real-time" interaction between employees. These advances have 
triggered subsequent rounds of outsourcing, as well, which began with manufacturing operations, but now increasingly include the once considered "safe" jobs of white collar, professional knowledge work (Burke and Ng, 2006).

To complicate matters further, major demographic and social shifts associated with the global workforce, the rise in dual income couples, the aging of the Baby Boomers and the convergence of four generations in today's workplace have introduced additional complexities and challenges into how organizations manage their people. While organizations have benefited from this period of change by way of increased productivity and profitability, there have also been negative impacts on the psyche of the workforce. Job loss, questions about job security, increased anxiety and continued exposure to ambiguity are only some of the many effects that comprise the shadow of this era. These dynamics, complexities and diversities that are now the characteristic of operational environment, are diffusing into the organization thereby making increasing demands on management and leadership competencies at all organizational levels. Mayer, Salovey, and Caruso, (2002), defined emotional intelligence as "the ability to monitor one's own and others' feelings and emotions, to discriminate among them, and to use this information to guide one's thinking and actions." In short, it is theorized that individuals have varying abilities to recognize, process, and extrapolate emotional information, thus leading to variations in how different individuals react to the same type of emotional stimuli. Emotional intelligence (EI) has emerged as a construct that is of interest to both academics and practitioners and has become one of the most topical areas in psychological research. Afolabi (2004) contend that emotional intelligence is not a single trait or ability rather, a composite of distinct emotion reasoning abilities. Perceiving emotions consist of recognising and interpreting the meaning of various emotional states, as well as their relations to other sensory experiences. Understanding emotions involve comprehension of how basic emotions are blended to form complex emotions. Regulating emotions encompasses the control of emotions in oneself and in others. An individual's emotional intelligence is an indicator of how he or she perceives, understands and regulates emotions.

The development of leadership competencies should be based on the global business strategy which determines what kind of presence is desirable, how many and what types of jobs, projects, task forces, and other types of interactions exist (McCall \& Hollenbeck, 2012). Competency development process should start from an analysis of the dynamics of the environment and the core competencies, continuing to identifying the profiles of resources and ending with identification of necessary competencies for specific jobs/functions. Leadership competencies are observed when a person demonstrates the competencies that constitute selfawareness, self-management, social awareness and social skills at appropriate times and ways in sufficient frequency to be effective in the situation. Most frequently in existing competency, frameworks which indicates that emotional intelligence represents a major component of global leadership competency. Much in line with these are personal attributes which underpin, and determine how and when, knowledge and skills will be used (Cannavaciulo et al., 2003). Understanding various attributes of leadership competencies and their interaction is essential for organizational leader's performance and in order for these organizations to work effectively in today's global business environment. Although the need to develop leaders with adequate competencies has become obvious in recent years (Morrison, 2013), there is still a significant gap between the international human resource requirements of a competent leaders and their organization's objectives realization

\section{STATEMENT OF THE PROBLEM}

Employers and employees interact in a multicultural environment, this differences suggest that organizational leaders must possess emotional competences, which influence and ease 
relationships between people, allow a better social cohesion, an emotional self-control and an "alphabetisation" of emotional states. In the absence of this, organizational leaders may wallow in self-praise due to poor self management and this impede on their self and social awareness. When considered holistically, these can result in a drastic redefining of the fundamental relationship between employer and employee, characterized as the "psychological contract.

\section{OBJECTIVES OF THE STUDY}

The central objective of this paper is to examine the effects emotional intelligence has on leadership competence. Its specific objectives include;

i. Examine the effects self management has on self awareness leadership competence

ii. Examine the effects relationship management has on social awareness leadership competencies

\section{RESEARCH QUESTIONS}

i. What is the effect of self management on self awareness leadership competence?

ii. What is the effect relationship management on social awareness leadership competencies?

\section{HYPOTHESES}

Ho1: Self management does not have significant effect on self awareness leadership competence

Ho2: $_{\text {: }}$ Relationship management does not have significant effect on social awareness leadership competencies

\section{Conceptual framework}

\section{Emotional Intelligence}

Emotions are implicated in many aspects of everyday life. Their impact and relevance, in combination with the subjective nature of emotional experience, suggest it is important to work towards a comprehensive scientific model of emotion-related self-perceptions, as envisaged in the trait emotional self-efficacy conceptualization (Petrides, Pita, \& Kokkinaki, 2007). Emotional intelligence basically illustrates and describes the capacity to join emotions with reasoning to arrive at a decision. Cognitive ability or competence, measured as intelligence quotient (IQ), often does not explain the difference between average and superior work performance, including that of a leader, and this hence indicates that there is another dimension that contributes towards effective leadership (Cameron, 2008). Reuven Bar-On (2010) argues that emotional intelligence forms an essential part of positive psychology, and has a positive impact on performance, happiness, well-being, and the quest for a more meaningful life, all of which are key areas of happiness in positive psychology. Cameron elaborates further by stating that in line with positive psychology, positive and emotional intelligent leadership strategies can help with creating a positive organizational outcome. Ashkanasy and Daus (2005) provide a four point summary of emotional intelligence:

$>$ It is not the same, but positively associated to other intelligences

$>$ It differs from person to person

$>$ It progresses and develops over a person's life and may be improved by means of training and development initiatives

$>$ It involves the ability to recognize and observe emotions in oneself or others, as well as the competence and skill to comprehend and handle these sentiments effectively 
There are different approaches to emotional intelligence, namely an ability-based approach (Caruso, 2003) as well as a trait-based approach (Petrides, 2009). The following short explication describes and distinguishes between the three types of emotional intelligence as well as mentioning one measurement tool each used to evaluate this type of emotional intelligence. As trait emotional intelligence is the model used in the research study at hand, the literature review then focuses in more detail on trait emotional intelligence and the measurement tool used in this regard.

\section{Models of Emotional Intelligence}

Ability emotional intelligence: this refers to emotion related cognitive ability, which is measured by means of performance tests (Petrides, Pita, \& Kokkinaki, 2007). Ability emotional intelligence, called "cognitive-emotional ability" by Petrides and Furnham (2001) refers to concrete capabilities connected to emotions. To measure this construct, Mayer and Salovey, developed an emotional intelligence ability model assessing emotional intelligence as a kind of cognitive intelligence. The instrument is known as the Mayer-Salovey-Caruso Emotional Intelligence Test (MSCEIT) (Mayer \& Salovey, 1997). It is based on a number of emotion-based problem-solving items (Conte, 2005) and measures constructs such as perceiving emotions, using emotions, understanding emotions and managing emotions. The model of ability-based emotional intelligence has been criticized for missing predictive validity and for being scientifically unsupported.

The mixed model of emotional intelligence, introduced by Goleman (1998), refers to emotional intelligence as learned abilities, and allures to the belief that individuals are born with a certain level of emotional intelligence that can be further enhanced through training. It focuses on a wide range of competencies and skills, which are grouped under the following four main constructs: self-awareness, self-management, social awareness and relationship management. The ECI, Emotional Competency Inventory, was developed by Boyatzis and Goleman in 1999 to measure emotional competencies and positive social behaviours. To date, no peer reviewed empirical studies have been forthcoming (Conte, 2005), and therefore this tool is not given any serious consideration.

Trait emotional intelligence focuses on the emotion related character and self-perceptions of individuals and is measured by a self-report. It consists of individuals" own perceptions of their abilities and is located in the lower order of personality, and hence trait emotional intelligence is not an ability-based model. According to Petrides, trait emotional intelligence is the only effective definition of emotional intelligence that acknowledges the intrinsic bias and subjectiveness of emotional experience. Trait EI theory enjoys widespread empirical support and consistently replicated findings from numerous studies that are theoretically driven, methodologically sophisticated, and independently conducted. According to Petrides and Furnham (2001) trait EI entails reaction-related behavioural inclinations and self-perceived capabilities referring to typical performance most effectively considered through own account. Petrides and Furnham identify this as "emotional self-efficacy". According to this view, the selfrating agrees with the subjective character of emotions.

\section{Leadership Competencies}

Leadership is a subject with very many facets and aspects. At the very essence, leadership is about understanding and managing human behaviour. Hitt (1993), states that leadership is generally defined as the art or process of influencing people so that they will strive willingly towards the achievement of group goals. Groenewald (2008) concurs by stating it is the art of moving people and situations profitably. Accordingly, excellent leadership is about movement, where all stakeholders move towards defined outcomes. Ilbury (2004) describes leadership as 
follows: A leader is someone who emerges, especially in times of uncertainty, because they offer ways forward that others haven't yet identified and will therefore enthusiastically follow.........A great leader shows opportunity where others only see confusion and uncertainty. It follows that leadership is a highly complex process, calling for a set of finely developed skills, as leadership mistakes and poor leadership are costly, both in terms of human and organizational costs. Meyer (2004) considers various aspects concerning leadership, which includes the need to understand leadership within a context (e.g. spiritual, emotional, organizational and cultural) as well as a specific point in time. A host of issues are considered such as enabling ordinary people to do extraordinary things and setting them up for success, the ability to manage through exceptionally difficult times and crises, getting people involved in a goal with a specific purpose, helping people to understand the history (where they come from), current situation and the outlook and prospects (where they are going to), as well as understanding the role and influence of follower

\section{Dimensions of Leadership Competence}

Self Awareness Leadership Competencies: Different self-awareness leadership competencies have variable outcomes under different circumstances. Self-awareness leadership competencies should be adapted to the particular demands of the situation, the particular requirements of the people involved and the particular challenges facing the organization. The major self-awareness leadership competencies include: Leadership competencies, transactional Leadership competencies, democratic leadership competencies, autocratic leadership competencies (Thisera, 2013). Autocratic or task-oriented Leadership competencies is multifaceted and encompasses a diverse range of behaviors including assigning followers to particular jobs, emphasizing deadlines, checking that followers observe rules and regulations, setting deadlines, and pressuring followers to work hard. Transactional leader influenced employees through the exchange of a good or service that serve as reward and promotions for good work or punishment and undesired action for underperformers. In democratic or employee oriented leadership competencies, leaders hold a good personal relationship with subordinates. A democratic leader takes an interest in the subordinates and likes to ensure that they achieve their goal (Thisera, 2013). On the other hand, leadership competencies influence people by promoting higher levels of intrinsic value associated with goal accomplishment, emphasizing the linkages between employees' effort and goal achievement, and creating a higher level of personal commitment on the part of the leader and followers to common vision, mission, and organization goals. Transformational leaders stimulate followers to perform beyond the level of expectations. The style is composed of four dimensions of ideals influence, inspirational motivation, intellectual stimulation and individualized consideration (Eisenbach, Watson \& Pillai, 2009).

Social Awareness Leadership Competencies: A social awareness leadership competency has two elements. First, ethical leaders must act and make decisions ethically. Secondly, ethical leaders must also lead ethically - in the ways they treat people in everyday interaction, in their attitudes, in the ways they encourage, and in the directions in which they steer their organizations or institutions or initiatives (Wang, Tsui \& Xin, 2011). An ethical Leadership competency is both visible and invisible. The visible part is in the way the leader works with and treats others, in his behavior in public, in his statements and his actions. The invisible aspects of Social awareness leadership competencies lie in the leader's character, in his decision-making process, in his mindset, in the set of values and principles on which he draws, and in his courage to make ethical decisions in tough situations. Social awareness leadership competencies demand ethical behavior all the time, not just when someone's looking; and they're ethical over time, proving again and again that ethics are an integral part of the 
intellectual and philosophical framework they use to understand and relate to the world. The major distinguishing feature of Social awareness leadership competencies is its stress on characterized moral perception, moral judgment, moral management, and moral impression. Social awareness leadership competencies is mostly related with self-actualization, moral relationship, moral perception, and unbiased dealing (Parboteeah, Chen, Lin, Chen \&Chung, 2010).

\section{Emotions and leadership: The Role of Emotional Intelligence (EI)}

Emotional competence is particularly central to leadership, a role whose essence is getting others to do their jobs more effectively. Inter-personal ineptitude in leaders lowers everybody's performance: it wastes time, creates acrimony, corrodes motivation and commitment, and builds hostility and apathy. A leader's strengths or weaknesses in emotional competence can be measured in the gain or loss to the organization of the fullest talents of those they manage. (Goleman, 1998). There is growing evidence that a record number of executives are derailing from their careers (Rosete, 2007). Literature hints that emotional intelligence may offer some insights into success and failure of leaders. This is highlighted by the fact that there is an increasing interest in research to explore whether emotional intelligence makes someone a better leader.

Literature suggests that feelings and emotions play an important role in human behaviour. They influence judgments, memory and reasoning, among others. Increasingly, it is accepted that feelings also take on a more central role in the leadership process than what was previously considered. Goleman (1998) highlights that studies have shown effective leaders to use more emotional intelligence competencies than other people in leadership positions. Ogunyemi (2007) concurs and adds that especially those leaders whose job demands a high social interaction, need effective emotional intelligence. Literature by Goleman et al., (2002) advocates that up to $79 \%$ of leadership success in the USA is a direct consequence of a high emotional intelligence. It appears that leaders' level of emotional intelligence has an effect on their behaviour, which makes them either more or less successful leader. Stein and Book (2000), in research covering thousands of participants in more than 30 professions, found that $47-56 \%$ of success in a person's working- and private life can be accounted to the level of emotional intelligence of that person. They furthermore found that certain emotional competencies had a higher relevance than others in the occupational context, and that different jobs required different emotional intelligence competencies. The research revealed further, that emotional competencies are required for leadership positions differ across various professions. According to Goleman et al. (2002), emotional intelligence is an important part of being an effective leader, especially in the team context, diffusion of conflict constructively which promotes trust and co-operation among team members in this regard. A leader is someone with the power to project either shadow or light onto some part of the world and onto the lives of the people who dwell there. A leader shapes the ethos in which others must live, an ethos as light-filled as heaven or as shadowy as hell. A good leader is intensely aware of the interplay of inner shadow and light, lest the act of leadership do more harm than good.

If leaders are able to control their own emotions and practise self-control, they act as role models to their teams (Barling et al., 2000a), and hence have a positive impact on the team. The shadow side being the potential abuse of power, needs to be handled with utmost care by the leader and managed in such a way that at best it is avoided (Bower, 2010). Relationship approaches to leadership are inherently emotional and the quality of this relationship is enhanced if leaders have good emotional intelligence (Antonakis, Ashkanasy \& Dasborough, 2009). While a rational decision maker can do so without much consideration for emotions or feelings, research suggests that emotions are required to make sound decisions. They assist to 
weigh up choices and arrive at decisions. Feelings are intimately connected to the human experience. Feelings are intricately bound up in the ways people think, behave and make decisions. Leaders are humans who potentially experience the full range of emotions. Both, positive and negative moods and emotions serve numerous functions in people's lives. Likewise, both positive and negative moods and emotions can sometimes be the cause of human dysfunction. Understanding the relevance of emotions and the ability to manage and understand these, add to more effective leadership in organizations. A truly successful leader, however, needs more for universal leadership success. The ability to integrate intelligence and knowledge, leadership skills, geographical and cultural dimensions into the style displayed, makes for more effective leadership.

As has been described above, leadership is an emotion laden-process, for leaders as well as followers, and according to Ferguson and Kelley (2005) research has proven that higher levels of emotional intelligence make teams more effective and productive, create more resilience during changing times and add to an improved retention of talent in the organization. Goleman et al. (2002) identify fifteen different emotional intelligence competencies, which are allocated to four domains. They allure to the fact that while all good leaders possessed some excellent emotional competencies, very effective leaders generally possess numerous emotional competencies and traits, but there is no one single formula that guarantees leadership success. Moreover, leadership is situational, hence; different qualities may be required for different leadership contexts. However, effective leaders typically display at least one strength in each of the core areas of emotional intelligence. In Goleman's model these are self-awareness, selfmanagement, social awareness and relationship management, whereas in Petride's trait emotional intelligence fifteen factors are divided up differently into domains of emotionality, sociability, well-being and self-control (Goleman et al., 2002; Petrides, 2010).

\section{Theoretical Review}

Trait Theory: The trait theory attempted to identify specific physical, mental, and personality characteristics associated with Leadership competencies success, and it relied on research that related various traits to certain success criteria (Northouse, 2007). This theory argued that leaders are people who can fully express themselves while others cannot, and this is what makes them different from other people. A leader has the right combination of traits which makes him a good leader. The meaning of this theory is that the same leadership competencies attributes are applicable for leadership competencies on a battlefield, non-profitable organization, and profitable organizations. This theory is relevant to this study since it elaborates on the characteristics of a good leader. For instance, the theory posits that the character of a leader is what determines whether he/she will be a good or a bad leader. This theory addresses the variable leadership competencies.

\section{METHODOLOGY}

In conducting this study, descriptive survey approach was adopted and data was generated from a five point likert scale questionnaire. The study covered a population of one hundred and twenty three (123) members of staff of three selected banks in Owerri. Taro Yamene formula was used to select a sample of 94 respondents. Out of the 94 questionnaires distributed, 88 were correctly filled and returned; thereby given a questionnaire return rate of $93.62 \%$. The data gathered was analyzed with the kruskawalis $(\mathrm{H})$ test. The kruskawalis test is given as;

$$
T=H=\frac{12}{N(N+1)}_{i=1}^{k} \frac{R_{i}^{2}}{n_{i}} 3(N+1)
$$


The decision rule is to reject the null hypothesis if $\mathrm{H} \quad \stackrel{2}{2} \quad \begin{array}{ll}(k 1) \\ \text {, }\end{array}$

where $\mathrm{k}$ is the degrees of freedom.

SPSS OUTPUT FOR HYPOTHESIS ONE

\section{RESULTS}

NPAR TESTS

/K-W=SMandSWLC BY RANKS (1 5)

/STATISTICS DESCRIPTIVES

/MISSING ANALYSIS.

NPar Tests

Descriptive Statistics

\begin{tabular}{|l|r|r|r|r|r|}
\hline & \multicolumn{1}{|c|}{$\mathrm{N}$} & \multicolumn{1}{c|}{ Mean } & Std. Deviation & Minimum & Maximum \\
\hline SMandSWLC & 20 & 17.6000 & 7.75547 & 5.00 & 30.00 \\
RANKS & 20 & 3.0000 & 1.45095 & 1.00 & 5.00 \\
\hline
\end{tabular}

\section{Kruskal-Wallis Test}

\begin{tabular}{|l|l|r|r|}
\hline \multicolumn{1}{|c|}{ Ranks } \\
\hline & RANKS & \multicolumn{1}{|c|}{ N } & Mean Rank \\
\hline & 1.00 & 4 & 2.63 \\
SMandSWL & 2.00 & 4 & 11.00 \\
C & 3.00 & 4 & 13.88 \\
& 4.00 & 4 & 17.88 \\
& 5.00 & 4 & 7.13 \\
& Total & 20 & \\
\hline
\end{tabular}

\begin{tabular}{|l|r|}
\hline \multicolumn{2}{|c|}{ Test Statistics ${ }^{\mathbf{a}, \mathbf{b}}$} \\
\hline Chi-Square & SMandSWLC \\
Df & 15.984 \\
Asymp. Sig. & 4 \\
\hline
\end{tabular}

a. Kruskal Wallis Test

b. Grouping Variable:

RANKS

Discussion: from the SPSS output above, $\mathrm{H} \quad \underset{(k 1)}{2}$ (i.e $0.05>0.003)$, we therefore reject the null hypothesis in line with the rule and conclude that there is a significant self management has on significant effect on self awareness leadership competence

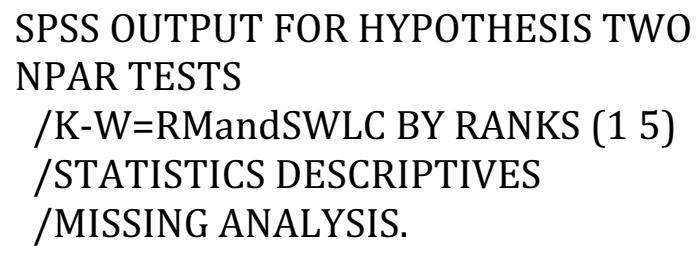

NPar Tests

Descriptive Statistics

\begin{tabular}{|l|r|r|r|r|r|}
\hline & \multicolumn{1}{|c|}{$\mathrm{N}$} & \multicolumn{1}{|c|}{ Mean } & Std. Deviation & Minimum & Maximum \\
\hline RMandSWLC & 25 & 17.6000 & 7.72981 & 5.00 & 30.00 \\
RANKS & 25 & 3.0000 & 1.44338 & 1.00 & 5.00 \\
\hline
\end{tabular}




\section{Kruskal-Wallis Test}

\begin{tabular}{|r|r|r|r|}
\hline \multicolumn{1}{|c|}{ Ranks } \\
\hline & RANKS & N & Mean Rank \\
\hline 1.00 & 5 & 3.20 \\
2.00 & 5 & 13.50 \\
RMandSWLC & 3.00 & 5 & 17.90 \\
& 4.00 & 5 & 22.00 \\
& 5.00 & 5 & 8.40 \\
Total & 25 & \\
\hline
\end{tabular}

\section{Test Statistics ${ }^{a, b}$}

\begin{tabular}{|l|r|}
\hline & $\begin{array}{c}\text { RMandSWL } \\
\text { C }\end{array}$ \\
\hline Chi-Square & 20.606 \\
Df & 4 \\
Asymp. Sig. & .000 \\
\hline
\end{tabular}

a. Kruskal Wallis Test

b. Grouping Variable:

RANKS

Discussion: from the SPSS output above, $\mathrm{H} \quad \underset{(k 1)}{2}$ (i.e $0.05>0.000)$, we therefore reject the null hypothesis in line with the rule and conclude that relationship management has significant effect on social awareness leadership competencies

\section{CONCLUSION AND RECOMMENDATIONS}

Leadership competence is an integral component of organizational performance, it was concluded in this study that the emotional state of the leader has significant effect on his/her competence. In line with the findings and conclusion, the study recommends that;

i. Leaders should demonstrate emotional self-control, transparency, adaptability, initiative and be optimistic. These are the inevitable high personal standards that drives them to constantly seek performance improvements, hence; enhancing their goal achievement orientation

ii. To develop quality social awareness, leaders should strive to exhibit conflict management skills, be inspirational, drive changes in their environment and develop others. These helps to generate an atmosphere of friendly collegiality and make them models of respect, helpfulness, and co-operation. Thereby drawing others into active, enthusiastic commitment to the collective effort, and build spirit and identity.

\section{References}

Antonakis, J., Ashkanasy, N.M., \& Dasborough, M.T. (2009). Does leadership need emotional intelligence? The Leadership Quarterly, 20, 247-261.

Ashkanasy, N., \& Daus, C.S. (2005). Rumors of the death of emotional intelligence in

Organizational behavior are vastly exaggerated. Journal of Organizational Behaviour, 26, 441-452.

Barling, J., Slater, F., \& Kelloway, E.K. (2000b). Transformational Leadership and

emotional intelligence: an exploratory study. Leadership and Organizational Development Journal, 21(3), 157-161.

Burke, R.J. \& Ng, E. (2006). The changing nature of work and organizations: Implications for human resource management. Human Resource Management Review, 16, 86-94.

Cameron, K.S. (2008). Positive Leadership. San Francisco: Berret-Koehler 
Caruso, D.R. (2003). Defining the Inkblot called Emotional Intelligence. Comment on RJ Emmerling and D Goleman, „Emotional Intelligence: Issues and Common Misunderstandings“. Retrieved August, 2010 from http://www.eiconsortium.org

Cartwright, S. \& Holmes, N. (2006). The meaning of work: The challenge of regaining employee engagement and reducing cynicism. Human Resource Management Review, 16, 199-208

Conte, J.M. (2005). A review and critique of emotional intelligence measures. Journal of Organizational Behavior, $26,433-440$.

Eisenbach, R., Watson, K. \& Pillai, R. (2009). Transformational leadership in the context of organizational change. Journal of Organizational Change Management, 12(2), 80-89

Goleman, D. (1998). Working with emotional intelligence. New York: Bantam.

Goleman, D., Boyatzis, R., \& McKee, A. (2002). Primal Leadership. Boston: Harvard Business School Press.

Groenewald, A. (2008). Moving towards your leadership destiny. Johannesburg: 30 Degree South Publishers.

Hitt, W.D. (1993). The model leader. Columbus: Battelle.

Ilbury, C. (2004). Leadership for the new economy. In T.N.A. Meyer \& I. Boninelli, (eds). (2004). 45-59.

Conversations in Leadership. Randburg: Knowres Publishing

Mayer, J.D., \& Salovey, P. (1997). What is emotional intelligence: implications for educators. In P. Salovey \& D. Sluyter, (eds), Emotional development, emotional literacy, and emotional intelligence. New York: Basic Books.

Mayer, J. D., Salovey, P., \& Caruso, D. R. (2002). Mayer-Salovey-Caruso Emotional Intelligence Test: Manual. Toronto, Ontario, Canada: Multi-Health Systems

McCall Jr., M.W., \& Hollenbeck, G.P. (2012).Developing the expert leader. CEO Publication, G 07-20(530). Retrieved from: http://stage.marshall. usc.edu/assets/048/9958.pdf

Meyer, T.N.A. (2004). The Nature of Leadership. In T.N.A. Meyer \& I. Boninelli (eds). (2004). Conversations in Leadership. Randburg: Knowres Publishing

Northouse, G. (2007). Leadership theory and practice. (4th ed.) Thousand Oak, London, New Delhe, Sage publication

Ogunyemi, A.O. (2007). Nurturing leaders emotional intelligence through brainstorming and emotional mastery programmes: implications for human resource management. Paper presented at the Conference of Counselling Association of Nigeria, CASSON, held at Coveant University Otta from 14-17 August 2007

Petrides, K.V. (2009). Technical Manual for the Trait Emotional Intelligence Questionnaire (TEIQue). London: London Psychometric Laboratory.

Petrides, K.V. \& Furnham, A. (2001). Trait emotional intelligence. Psychometric investigation with reference to established trait taxonomies. European Journal of Personality, 15, 425-448.

Petrides, K.V., Pita, R. \& Kokkinaki, F. (2007). The location of trait emotional intelligence in personality factor space. British Journal of Psychology, 98, 273-289.

Reauven B. (2010). Emotional intelligence: an integral part of positive psychology. South African Journal of Psychology, 40(1), 54-862.

Stein, S.J., \& Book, H.E. (2000). The EQ edge: Emotional Intelligence and your Success. Toronto: Stoddard.

Thisera, A. B. (2013). Does leadership make a difference to organizational performance? Administrative Science Quarterly, 33, 388-400.

Wang, H., Tsui, A. S., \& Xin, K. R. (2011).CEO leadership behaviors, organizational performance, and employees' attitudes. The Leadership Quarterly, 22(1), 92-105 